\title{
PENGARUH PROGRAM PENGEMBANGAN KARIR DAN MOTIVASI KERJA TERHADAP KINERJA KARYAWAN PT. PANGKATAN INDONESIA
}

\author{
Bayu Eko Broto \\ Dosen Tetap Sekolah Tinggi Ilmu Ekonomi (STIE) Labuhanbatu
}

\begin{abstract}
Abstrak:
Kebutuhan pada perubahan-perubahan yang harus dilaksanakan dilingkungan karyawan, reorganisasi dan lambatnya kemajuan dalam pengalaman yang sangat dirasakan oleh karyawan akan membentuk persepsi atas program pengembangan karir dan motivasi kerja karyawan di perusahaan. Bila karyawan tidak memperoleh harapannya tentang program pengembangan karir dan motivasi kerja maka akan merubah harapan dan prilakunya.Setelah terjadinya perubahan pengelolaan di PT. Pangkatan Indonesia dari SIPEP Group menjadi PT. EVANS Indonesia, banyak memberikan peluang dan kesempatan terhadap peningkatan pengembangan karir dan motivasi kerja karyawan, namun belum diketahui sampai sejau mana pengaruhnya terhadap peningkatan kinerja karyawan. Oleh karena itu dalam penelitian ini diamati bagaimana pengaruh program pengembangan karir dan motivasi kerja terhadap kinerja karyawan PT. Pangkatan Indonesia tersebut.Metode penelitian ini menggunakan metode deskriptif kuantitatif dengan pendekatan studi kasus yang berbentuk desain kausal simetris yang bersifat deskriptif eksploratif. Populasi dalam penelitian ini adalah seluruh karyawan PT. Pangkatan Indonesia yang berjumlah 370 orang dan sampel penelitian ini diambil sebanyak 79 orang karyawan. Pengumpulan data dilakukan melalui observasi, kuesioner, dan interview dengan menggunakan pengukuran skala Likert.Data dianalisis dengan menggunakan Analisis Regresi Linier Berganda yang diolah dengan menggunakan program statistic SPSS Versi 20.0 yang meliputi pengujian hipotesis dan uji parsial dengan tingkat kepercayaan 95\%.Berdasarkan hasil pengujian hipotesis baik uji $F$ dan uji $t$ diperoleh bahwa tidak terdapat pengaruh yang signifikan antara variabel program pengembangan karir $\left(X_{1}\right)$ terhadap kinerja karyawan PT. Pangkatan Indonesia, dan sebaliknya terdapat pengaruh yang signifikan antara motivasi kerja $\left(X_{2}\right)$ terhadap kinerja karyawan PT. Pangkatan Indonesia. Hal ini menunjukkan bahwa kebijakan pengembangan motivasi kerja yang diterapkan manajemen PT. Pangkatan Indonesia mempengaruhi tingkat kinerja karyawan yang terlihat melalui dedikasi, loyalitas dan prestasi kerja karyawan.
\end{abstract}

Kata Kunci: $\quad$ Program pengembangan karir, motivasi kerja dan kinerja karyawan.

\section{Abstract:}

The need for changes that must be implemented within the employee's environment, reorganization and the slow progress in the highly perceived 
experience of employees will shape the perception of career development programs and employee work motivation in the company. If the employee does not get his expectations about career development programs and work motivation then change his expectations and behavior. After the change of management in PT. Pangkatan Indonesia from SIPEP Group to PT. EVANS Indonesia, provides many opportunities and opportunities to improve career development and employee work motivation, but not yet known to how much influence on the improvement of employee performance. Therefore in this study observed how the influence of career development programs and work motivation on employee performance PT. Pangkatan Indonesia. This research method uses descriptive quantitative method with case study approach which is in the form of symmetric causal design which is descriptive explorative. Population in this research is all employees of PT. Pangkatan Indonesia amounted to 370 people and the sample of this study was taken as many as 79 employees. Data collection was done through observation, questionnaire, and interview using Likert scale measurement. Data were analyzed by using Multiple Linear Regression Analysis which was processed by using SPSS Version 20.0 statistic program which includes hypothesis test and partial test with $95 \%$ confidence level. Based on the results of hypothesis testing both $F$ test and t test obtained that there is no significant influence between career development program variables (X1) on the performance of employees of PT. Pangkatan Indonesia, and vice versa there is a significant influence between work motivation (X2) on the performance of employees of PT. Pangkatan Indonesia. This indicates that the policy of work motivation development applied by PT. Pangkatan Indonesia affect the level of employee performance that is seen through dedication, loyalty and employee.

\section{Keywords:Career development programs, work motivation and employee performance.}

\section{PENDAHULUAN}

Perkebunan merupakan usaha industri yang mendayagunakan kemampuan untuk mendukung semua sektor pembangunan, tidak hanya dari segi kuantitas tetapi juga dari segi kualitas dan mutu.Kelapa sawit merupakan salah satu komoditas andalan subsektor perkebunan yang menarik perhatian serius pemerintah, pihak investor serta petani terutama sejak dekade 1990-an. Perkembangan kelapa sawit di Indonesia mengalami pertumbuhan yang cukup pesat sejak tahun1970 terutama periode 1980-an hingga pada saat ini. Semula pelaku perkebunan kelapa sawit terdiri dari Perkebunan Besar Negara (PBN) namun pada tahun yang sama pula dibuka Perkebunan Besar Swasta (PBS) dan Perkebunan Rakyat (PR) melalui pola PIR (Perkebunan Inti Rakyat) dan selanjutnya berkembang pola swadaya.

PT. Pangkatan Indonesia adalah sebuah Badan Usaha Milik Swasta (BUMS) yang berada di bawah Pengelola PT. Evans Indonesia yang bergerak dalam bidang perkebunan dan pengolahan kelapa sawit.Selain dengan melaksanakan pengembangan Karir, untuk meningkatkan prestasi kerja karyawan, perusahaan harus mampu memotivasi karyawan dengan baik. Motivasi ini sangat ditentukan oleh sikap dan tindakan perusahaan dalam 
melaksanakannya. Meskipun demikian, jika motivasi yang ada tidak sesuai yang diinginkan karyawan maka akan menyebabkan turunnya prestasi kerja karyawan. Pemberian motivasi oleh perusahaan sangat penting untuk memberi dorongan kepada karyawan agar lebih berprestasi dalam bekerja.

Dengan adanya kelemahan dan Motivasi yang diberikan kepada karyawan oleh PT. Pangkatan Indonesia berpola achievement motivation yaitu motivasi untuk kemajuan dan pertumbuhan karyawan dan menggunakan asas motivasi pengakuan dan perhatian timbal balik dengan maksud memberikan perhargaan, balas jasa dan pengakuan yang tepat serta wajar kepada karyawan atas prestasi kerja yang telah dicapainya. Sedangkan metode motivasinya langsung seperti pemberian penghargaan, tunjangan hari raya, bonus tidak langsung seperti pemberian ruangan kerja yang nyaman, suasana pekerjaan yang serasi dan penempatan kerja yang tepat.

Melalui pengembangan Karir dan motivasi karyawan, PT. Pangkatan Indonesia dapat mengharapkan pada karyawannya untuk dapat bekerja lebih baik dan berprestasi lebih tinggi dalam rangka mencapai sasaran dan tujuan perusahaan yang telah ditetapkan.Kinerja karyawan yang terjadi di PT. Pangkatan Indonesia berkaitan dengan permasalahan kinerja karyawan, yaitu disiplin kerja yang rendah, dapat dilihat dalam hal mentaati peraturan masuk kerja dan waktu keluar kerja, banyaknya pegawai yang tidak mengikuti apel pagi, serta penggunaan jam kerja yang kurang efektif. Berikut ditunjukkan data absensi tahun 2016 (dalam hitungan orang)karyawan PT. Pangkatan Indonesia:

Tabel 1.1. Data Absensi Karyawan

\begin{tabular}{|c|c|c|c|c|}
\hline \multirow{2}{*}{ Bulan } & \multicolumn{3}{|c|}{ A sumulasi SIA } & \multirow{2}{*}{ Jumlah Karyawan } \\
\cline { 2 - 4 } & Sakit & Izin & Alfa & 365 \\
\hline Januari & 30 & 6 & 3 & 370 \\
\hline Februari & 29 & 1 & 7 & 370 \\
\hline Maret & 27 & 2 & 5 & 370 \\
\hline April & 23 & 3 & 3 & 370 \\
\hline Mei & 20 & 7 & 7 & 370 \\
\hline Juni & 10 & 5 & 4 & \\
\hline
\end{tabular}




\begin{tabular}{|c|c|c|c|c|}
\hline Juli & 14 & 2 & 3 & 370 \\
\hline Agustus & 14 & 0 & 4 & 370 \\
\hline September & 14 & 3 & 3 & 370 \\
\hline Oktober & 15 & 4 & 4 & 370 \\
\hline Nopember & 23 & 6 & 3 & 370 \\
\hline Desember & 24 & 7 & 4 & 370 \\
\hline Rata-Rata & $\mathbf{1 8}$ & $\mathbf{4}$ & $\mathbf{4}$ & \\
\hline
\end{tabular}

Sumber : PT. Pangkatan Indonesia

Dari permasalahan diatas, kita dapat melihat bahwa perilaku kerja karyawan di PT. Pangkatan Indonesia menunjukkan rendahnya kinerja karyawan yang kurang menggembirakan. Oleh karena itu, diperlukan upaya dalam mewujudkan prestasi kerja yang baik yaitu dengan adanya pelaksanaan pengembangan karir dan motivasi sehingga kerugian-kerugian yang disebabkan oleh penurunan prestasi kerja karyawan dapat diminimalisir.

Tujuan dari penelitian iniadalah untuk : (1) Untuk mengetahui Pengembangan Karir di PT. Pangkatan Indonesia,(2)Untuk mengetahui Motivasi Kerja di PT. Pangkatan Indonesia, (3) Untuk mengetahui Kinerja Karyawan PT. Pangkatan Indonesia, (4) Untuk mengetahui besarnya Pengaruh Pengembangan Karir dan Motivasi Kerja Terhadap Kinerja Karyawan baik secara simultan maupun parsial di PT. Pangkatan Indonesia.

Tinjauan pustaka dalam penelitian ini sebagai berikut:

Pengembangan karir adalah pendekatan formal yang diambil organisasi untuk memastikan bahwa orang-orang dengan kualifikasi dan pengalaman yang tepat tersedia pada saat dibutuhkan, karena perencanaan dan pengembangan karir menguntungkan individu dan organisasi (Simamora, 2006). Menurut Andrew J. Dubrin (1982) dalam Prabu (2004) dikemukakan bahwa pengembangan Karir adalah aktivitas kepegawaian yang membantu pegawai-pegawai merencanakan Karir masa depan mereka di perusahaan agar perusahaan dan pegawai yang bersangkutan dapat mengembangkan diri secara maksimum. Siagian (2001) mendefinisikan pengembangan karir adalah suatu langkah yang ditempuh perusahaan untuk menghadapi tuntutan tugas karyawan dan untuk menjawab tantangan masa depan dalam mengembangkan sumber daya manusia di perusahaan yang merupakan suatu keharusan dan mutlak diperlukan.

Tujuan pengembangan Karir dikemukakan oleh Andrew J. Dubrin (1982) dalam Prabu (2004) adalah :Membantu dalam pencapaian tujuan individu dan perusahaan dalam pengembangan Karir karyawan yang merupakan hubungan timbal balik yang bermanfaat bagi kesejahteraan karyawan dan tujuan perusahaan dapat tercapai. Seorang pegawai yang sukses dengan prestasi kerja sangat baik kemudian menduduki posisi jabatan yang lebih tinggi, hal ini berarti tujuan perusahaan dan tujuan individu tercapai.

Motivasi didefinisikan oleh Gomes (2003: 178) yaitu hal-hal yang berkaitan dengan tingkat usaha yang dilakukan oleh seseorang dalam mengejar suatu tujuan. Wexley dan Yulk dalam As'ad (2004) menjabarkan motivasi kerja adalah sesuatu yang menimbulkan semangat atau dorongan kerja. Menurut Mangkuprawira dan Hubeis (2007: 153) motivasi adalah dorongan yang membuat karyawan melakukan sesuatu dengan cara dan untuk mencapai tujuan tertentu. Tidak ada keberhasilan mengerjakan sesuatu, seperti mengelola karyawan, tanpa adanya motivasi baik dari manajer maupun dari karyawan.

Sedangkan faktor-faktor yang mempengaruhi motivasi yang dikemukakan oleh 
Maslow yang dikutip oleh As'ad, (2004), kebutuhan-kebutuhan manusia dapat digolongkan dalam lima tingkatan yaitu :

a. Kebutuhan Fisik (Physiological Needs)

Kebutuhan ini merupakan kebutuhan yang amat primer, karena kebutuhan ini telah ada dan terasa sejak manusia dilahirkan ke bumi, misalnya : sandang, pangan dan tempat berlindung, sex dan kesejahteraan individu.

b. Kebutuhan rasa aman (safety Needs)

Kalau ini atau dikaitkan dengan kerja maka kebutuhan akan keamanan jiwanya sewaktu bekerja. Selain itu juga organisasi aman akan harga yang ditinggal sewaktu mereka bekerja. Perasaan aman juga menyangkut terhadap masa depan karyawan.

c. Kebutuhan-kebutuhan sosial (Social Needs)

Manusia pada hakekatnya adalah makhluk sosial, sehingga mereka mempunyai kebutuhan-kebutuhan sosial

Pendapat dari Herzberg yang dikutip oleh Hadari (2003). Ada dua factor motivasi yang dapat memberikan kepuasan dalam bekerja yaitu : a. Motivational Factor (Motivators).

Dari faktor ini antara lain adalah faktor prestasi (achievement), factor pengakuan/penghargaan, faktor tanggung jawab, faktor memperoleh kemajuan dan perkembangan dalam bekerja khususnya promosi dan faktor pekerjaan itu sendiri. Dengan memahami faktor-faktor tersebut pemimpin dapat memotivasi bawahannya agar kegiatan mereka mencapai kepuasan yang diingikannya dan juga menguntungkan pencapaian tujuan organisasi.

b. Kebutuhan Kesehatan Lingkungan Kerja (Hygiene Factors).

Faktor ini dapat berbentuk upah/gaji, hubungan antara pekerja, supervise tehnis, kondisi kerja, kebijaksanaan organisasi dan proses administrasi organisasi.

Kinerja adalah hasil kerja secara kualitas dan kuantitas yang dicapai oleh seorang pegawai dalam melaksanakan tugasnya sesuai dengan tanggung jawab yang diberikan kepadanya (Mangkunegara, 2001). Kinerja karyawa menurut Robbins (2006) adalah apa yang telah dihasilkan oleh individu karyawan. Selain itu kinerja juga dapat diartikan dengan adanya kemampuan dan perbuatan dalam situasi tertentu, sehingga kinerja tersebut merupakan hasil keterkaitan antara usaha, kemampuan dan persepsi tugas.

Kinerja adalah hasil dari proses pekerjaan tertentu secara terencana ada waktu dan tempat dari karyawan serta organisasi bersangkutan (Mangkuprawira dan Hubeis, 2007: 153).

\section{METODE}

Dalam penulisan ini, teknik pengumpulan data yang penulis lakukan adalah sebagai berikut :

1. Metode Interview

Metode interview yaitu suatu metode pengumpulan data yang dilakukan dengan jalan mengadakan tanya jawab sepihak dan dikerjakan secara sistematik dan berlandaskan pada tujuan penelitian. Dalam penelitian ini dilakukan interview kepada karyawan PT. Pangkatan Indonesia sebelum dilakukan pengisian kuesioner sebagai verifikasi bahwa responden merupakan karyawan yang telah bekerja minimal selama 3 tahun.

2. Metode Observasi Langsung 
Metode observasi langsung merupakan suatu metode pengumpulan data dengan mengadakan pengamatan langsung (tanpa alat) terhadap gejala obyek yang diteliti, baik yang dilakukan dalam situasi sebelumnya maupun dalam situasi yang khusus diadakan. Penelitian ini melakukan observasi atau penga-matan langsung ke PT. Pangkatan Indonesia yang beralamat di Kampung Rakyat Aeknabara Kabupaten Labuhanbatu Provinsi Sumatera Utara.

3. Metode Kuesioner

Metode kuesioner merupakan metode pengumpulan data yang dilakukan dengan cara menghadapkan responden, terutama dalam hal yang berkaitan dengan masalah yang diteliti. Dalam penelitian ini kuesioner diberikan kepada 79 responden yang merupakan karyawan yang termasuk karyawan tetap baik karyawan kantor maupun karyawan lapangan PT. Pangkatan Indonesia.

\section{Uji Validitas}

Analisis validitas adalah suatu ukuran yang menunjukkan tingkat-tingkatkevalidan atau kesahihan suatu instrumen (Arikunto, 2002: 144). Uji validitasdalam penelitian ini menggunakan korelasi Product Moment Pearson denganmenggunakan program SPSS versi 13.

Nilai $r$ kemudian dikonsultasikan dengan $r_{\text {tabel }}$ untuk taraf $\square=0,05$. Bila $r_{\text {hitung }}$ dari rumus di atas $>r_{\text {tabel }}$ maka dapat disimpulkan bahwa instrumen tersebut valid, dan sebaliknya. Setelah didapat harga koefisien validitas maka harga tersebut diinterprestasikan terhadap kriteria dengan mengunakan tolak ukur yang dibuat Guilford (Suherman, 2003) seperti pada Tabel berikut:

Tabel 1.2. Klasifikasi Interpretasi Koefisien Validitas

\begin{tabular}{|c|c|}
\hline Besarrhitung & Interpretasi \\
$0,90 \leq r_{\text {hitung }} \leq 1,00$ & Validitas sangat tinggi \\
$0,70 \leq r_{\text {hitung }}<0,90$ & Validitas tinggi \\
$0,40 \leq r_{\text {hitung }}<0,70$ & Validitas sedang \\
$0,20 \leq r_{\text {hitung }}<0,40$ & Validitas rendah \\
$0,00 \leq r_{\text {hitung }}<0,20$ & Validitas sangat rendah \\
rhitung $<0,00$ & Tidak valid \\
\hline
\end{tabular}




\section{Uji Reliabilitas}

Uji reliabilitas untuk mengetahui sejauhmana data dapat memberikan hasil yang relatif tidak berbeda bila dilakukan pengukuran kembali pada subyek yang sama atau dapat dikatakan untuk menunjukkan adanya persesuaian antara sesuatu yang diukur dengan jenis alat pengukur yang dipakai.Dalam menentukan realibilitas angket digunakan rumus Alpha menurut Arikunto (2008:171):

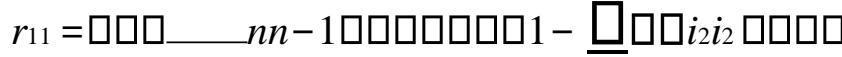

$$
\begin{aligned}
& \text { Dimana: } r_{11}=\text { reliabilitas instrumen } \\
& \square \square i^{2} \quad=\text { varian butir/item ke-i } \\
& \square i^{2} \quad=\text { varian total } \\
& \mathrm{N} \quad=\quad \text { Jumlah responden }
\end{aligned}
$$

Yang masing-masing nilai diatas dihitung dengan rumus:

$$
\sigma^{2}=\frac{\sum x^{2}-\left(\sum x\right)^{2}}{N}
$$

Dengan :

$$
\begin{array}{lll}
\mathrm{x} \quad= & \text { skor butir ke-i } \\
\mathrm{N}= & \text { banyak } \\
\text { responden } &
\end{array}
$$

Nilai $r$ kemudian dikonsultasikan dengan $r_{\text {tabel }}$ untuk taraf $\square=0,05$. Bila $r_{\text {hitung }}$ dari rumus di atas $>r_{\text {tabel }}$ maka dapat disimpulkan bahwa angket tersebut reliabel, dan sebaliknya. Setelah didapat harga koefisien reliabilitas maka harga tersebut diinterprestasikan terhadap kriteria dengan mengunakan tolak ukur yang dibuat Guilford (Suherman, 2003) seperti pada Tabel berikut:

Tabel 1.3. Klasifikasi Koefisien Reliabilitas

\begin{tabular}{|c|c|}
\hline Besar $_{11}$ & Interpretasi \\
\hline $\mathrm{r}_{11 \leq 0,20}$ & Reliabilitas sangat rendah \\
\hline
\end{tabular}




\begin{tabular}{|c|c|}
\hline $0,20 \leq \mathrm{r}_{11}<0,40$ & Reliabilitas rendah \\
\hline $0,40 \leq \mathrm{r}_{11}<0,70$ & Reliabilitas sedang \\
\hline $0,70 \leq \mathrm{r}_{11}<0,90$ & Reliabilitas tinggi \\
\hline $0,90 \leq \mathrm{r}_{11}<1,00$ & Reliabilitas sangat tinggi \\
\hline
\end{tabular}

Analisis Uji Korelasional untuk mengetahui seberapa besar keterkaitan antara kualitas air bersih terhadap tingkat kepuasan konsumen. Kriteria yang digunakan adalah terdapat korelasi atau pengaruh antara variable $\mathrm{X}$ dengan $\mathrm{Y}$ bila $: r_{\text {hitung }}>r_{\text {tabel. }}$ Untuk korelasi ini digunakan korelasi product moment, yaitu :

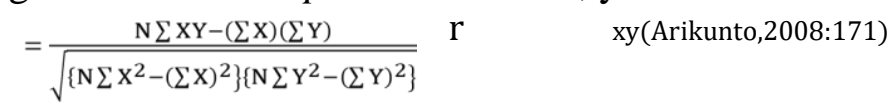

Koefisien korelasi antara variable $\mathrm{x}$ dan $\mathrm{y}$

$r_{x y} \quad: \quad$ Koefisien korelasi product moment

$\mathrm{X} \quad$ : Angka mentah variable bebas

$Y \quad$ : Angka mentah variable terikat

$\mathrm{N} \quad$ : Banyak sampel

Nilai $r$ kemudian dikonsultasikan dengan $r_{\text {tabel }}$ untuk taraf $\square=0,05$. Bila $r_{\text {hitung }}$ dari rumus di atas $>r_{\text {tabel }}$ maka dapat disimpulkan terdapat pengaruh atau korelasi.

\section{Pengujian Hipotesis Secara Serempak (Uji F)}

Adalah uji yang digunakan untuk menyatakan signifikansi pengaruh variabel bebas secara bersama-sama (simultan) terhadap variabel dependen (y) yang dilakukan dengan uji F yang diuji dengan taraf nyata $(\alpha)=5 \%$ (uji satu arah) dapat dilihat di bawah ini : a. Hipotesis yang akan diuji adalah sebagai berikut :

$\mathrm{H} 0: \beta 1,2,3=0$ artinya tidak ada pengaruh yang positif dansignifikan antara program pengembangan karir $\left(\mathrm{X}_{1}\right)$, dan motivasi kerja $\left(\mathrm{X}_{2}\right)$ terhadap kinerjakaryawan $(\mathrm{Y})$ secara simultan (bersama-sama)

Ha : $\beta 1,2,3>0$ artinya ada pengaruh yang positif dansignifikan antara program pengembangan karir $\left(\mathrm{X}_{1}\right)$, dan motivasi kerja $\left(\mathrm{X}_{2}\right)$ terhadap kinerjakaryawan (Y) secara simultan (bersama-sama)

b. Rumus pengujian untuk uji $\mathrm{F}$ :

$$
\begin{aligned}
& F=\frac{R 2 / k}{(1-R) /(n-k-1)}^{2} \\
& \text { Dimana : } \\
& \mathrm{k} \quad=\text { jumlah variabel bebas } \\
& \mathrm{R}^{2}=\text { koefisien determinasi }
\end{aligned}
$$




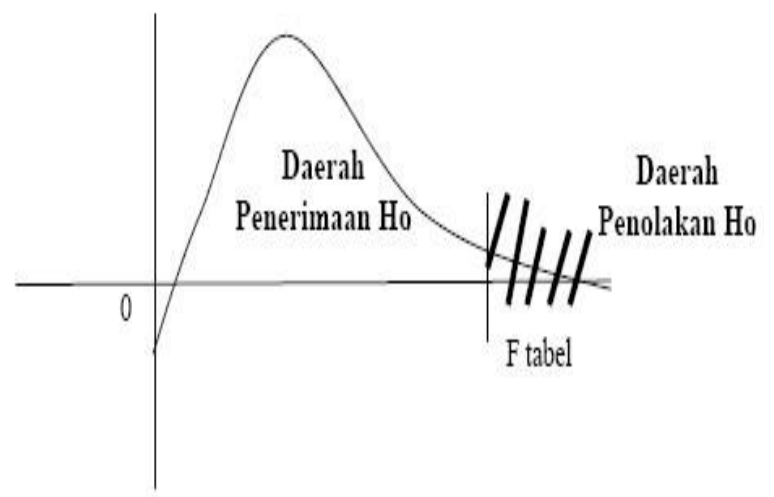

\section{Gambar 1.1 :Uji F Satu Arah}

- Apabila F hitung $\leq \mathrm{F}$ tabel, maka Ho diterima dan Ha ditolak artinya motivasi kerja (X1), kepemimpinan (X2) dan kesempatan pengembangan karir (X3) berpengaruh terhadap kinerja karyawan $(\mathrm{Y})$ secara simultan (bersama-sama)

- Apabila F hitung > F tabel, maka Ho ditolak atau Ha diterima artinya motivasi kerja (X1), kepemimpinan (X2) dan kesempatan pengembangan karir (X3) terhadap kinerja karyawan $(\mathrm{Y})$ secara simultan (bersama-sama).

\section{Pengujian Hipotesis Secara Parsial (Uji t)}

Hipotesis dalam penelitian ini adalah "Di duga terdapat pengaruh yang signifikan antara Adalah uji yang digunakan untuk menyatakan signifikansi pengaruh variabel bebas secara parsial terhadap variabel terikat. Untuk menguji variabel yang berpengaruh antara program pengembangan karir $\left(\mathrm{X}_{1}\right)$, dan motivasi kerja $\left(\mathrm{X}_{3}\right)$ terhadap kinerja karyawan $(\mathrm{Y})$, maka dilakukan pengujian dengan $\mathrm{t}$ test. Dapat dilihat pada langkah-langkah di bawah ini :

a. Hipotesis yang akan diuji dengan taraf nyata $(\alpha)=5 \%$ (uji dua arah)

Ho $: \beta=0$ artinya tidak ada pengaruh antara program pengembangan karir $\left(\mathrm{X}_{1}\right)$, motivasi kerja $\left(\mathrm{X}_{2}\right)$ terhadap kinerja karyawan $(\mathrm{Y})$ secara parsial (individu)

Ha : $\beta>0$ artinya ada pengaruh ada pengaruh antara program pengembangan karir $\left(\mathrm{X}_{1}\right)$, motivasi kerja $\left(\mathrm{X}_{2}\right)$ terhadap kinerja karyawan $(\mathrm{Y})$ secara parsial (individu)

b. Rumus pengujian untuk korelasi product moment

$$
t=\frac{r \sqrt{n-2}}{\sqrt{1-r^{2}}} \text { (Sudjana,2010: 109). }
$$

Dimana :

$\mathrm{r} 2$ = koefisien determinasi

$\mathrm{n} \quad=$ jumlah sampel 


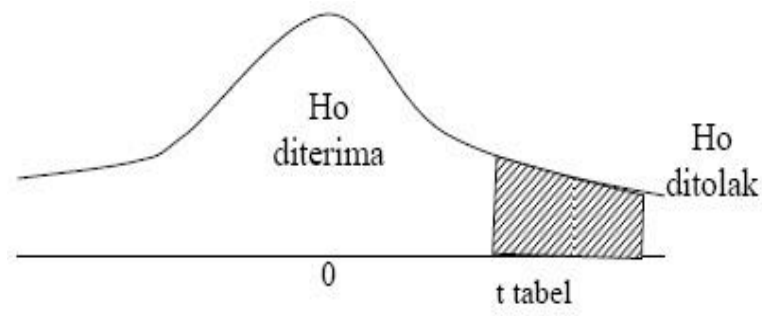

\section{Gambar 1.2 : Uji t Satu Arah (Sisi Kanan)}

- Apabila t hitung < - $\mathrm{t}$ tabel atau $\mathrm{t}$ hitung $>\mathrm{t}$ tabel, maka Hoditolak artinya ada pengaruh antara program pengembangan karir $\left(\mathrm{X}_{1}\right)$, motivasi kerja $\left(\mathrm{X}_{2}\right)$ terhadap kinerja karyawan (Y) secara parsial (individu)

- Apabila $\mathrm{t}$ hitung $>$ - $\mathrm{t}$ tabel atau $\mathrm{t}$ hitung $<\mathrm{t}$ tabel, maka Hoditerima, artinya tidak ada pengaruh antara program pengembangan karir $\left(\mathrm{X}_{1}\right)$, motivasi kerja $\left(\mathrm{X}_{2}\right)$ terhadap kinerja karyawan (Y) secara parsial (individu).

\section{HASIL DAN PEMBAHASAN Analisis Hasil Penelitian}

Untuk menganalisis data yang diperoleh dari hasil penelitian di lapangan, digunakan analisis kualitatif dan kuantitatif. Analisis kuantitatif digunakan untuk membuktikan hipotesis yang diajukan dengan menggunakan model analisis regresi linier berganda, sedangkan analisis kualitatif digunakan untuk menelaah pembuktian analisis kuantitatif.

Pembuktian ini dimaksudkan untuk menguji variasi dari model regresi yang digunakan dalam menerangkan variabel bebas $(\mathrm{X})$ terhadap variabel terikat $(\mathrm{Y})$ dengan cara menguji kemaknaan dari koefisien regresinya. Hasil perhitungan dengan menggunakan model regresi penuh (Full Model Regression) diperoleh dengan nilai koefisien regresi mengenai pengaruh program pengembangan karir dan motivasi kerja terhadap kinerja karyawan PT. Pangkatan Indonesia. 


\section{Tabel 1.4 Hasil Uji-F Analisis Regresi Berganda(Full Model Regression)}

\begin{tabular}{|c|c|c|c|c|c|c|c|c|c|c|c|}
\hline & & & & & Model St & Summary ${ }^{\circ}$ & & & & & \\
\hline Model & $R$ & $R$ & Adjus & & std. Error of the & & Chan & Ige Statistic & & & Durbin- \\
\hline & & Square & Squ & & Estimate & $\begin{array}{l}\text { R Square } \\
\text { Change }\end{array}$ & & hange $d$ & \begin{tabular}{l|l|l} 
df1 & $\mathrm{d}+2$ & \\
\end{tabular} & $\begin{array}{c}\text { Sig. } \\
\text { Change }\end{array}$ & Watson \\
\hline 1 &, $574^{\circ}$ &, 330 & & 312 & 2,869 & & 330 & 18,686 & \begin{tabular}{l|l|}
2 & 76 \\
\end{tabular} & $, 0,00$ & 1,972 \\
\hline a. Predi & ors: $\left(C_{0}\right.$ & nstant), M. & tivasi_k & erja, Penge & gembangan_Karir & & & & & & \\
\hline b. Depe & dentVar & iable: Kine & & & & & & & & & \\
\hline & & & & & & & & & & & \\
\hline & & & & & & ANOVA $^{2}$ & & & & & \\
\hline & & Model & & & Sum of Squares & df & Mean S & Square & $\mathrm{F}$ & & Sig. \\
\hline & & & Regr & ission & 307,515 & 2 & & 153,757 & 18,68 & &, $000^{\circ}$ \\
\hline & & 1 & Resi & & 625,371 & 76 & & 8.229 & & & \\
\hline & & & Tota & & 932,886 & 78 & & & & & \\
\hline & & a. Deper & dentVa & able: Kiner & & & & & & & \\
\hline & & b. Predic & tors: (C & nstant), Mo & Iotivasi_Kerja, Peng & ggembangan_Ka & & & & & \\
\hline 4 & & & & & & & & & & & \\
\hline & & & & & & Coefficients ${ }^{2}$ & & & & & \\
\hline & Model & & & $\begin{array}{r}\text { Unsta } \\
\text { Coe }\end{array}$ & $\begin{array}{l}\text { tandardized } \\
\text { oefficients }\end{array}$ & $\begin{array}{l}\text { Standardized } \\
\text { Coefficients } \\
\end{array}$ & $t$ & Sig. & & orrelations & \\
\hline & & & & $B$ & Std. Error & Beta & & & Zero-order & Pastial & 1) Part \\
\hline & & Constant) & & 7,030 & 2,448 & & 2,871 &, 005 & & & \\
\hline & 1 & $\begin{array}{l}\text { Fengemba } \\
\text { Karir }\end{array}$ & & 251 & 194 & .249 & 1,293 & 200 &, 549 & 147 & 47 $\quad 121$ \\
\hline & & Motivasi__ & & .447 & 250 &, 344 & 1,790 &, 077 & 561 & 201 & \begin{tabular}{l|l}
01 &, 168 \\
\end{tabular} \\
\hline & a. De & endenty & 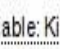 & & & & & & & & \\
\hline & & S & & Dalo & ร่ 20 & & & & & & \\
\hline
\end{tabular}

Selain itu persamaan regresi linier berganda di atas, terdapat nilai koefisien regresi variabel bebas $X$ adalah positif. Nilai koefisien $X$ yang positif artinya apabila terjadi perubahan pada variabel $\mathrm{X}$, akan menyebabkan perubahan secara searah pada variabel $\mathrm{Y}$.

Koefisien Regresi $\mathrm{X}_{1}$ (pendidikan dan pelatihan) sebesar 0,251 yang berarti bahwa jika $X_{1}$ (pengembangan karir) naik sebesar satu satuan, akan memberikan pengaruh terhadap kinerja karyawan sebesar koefisien pengalinya, dengan asumsi bahwa variabel lain dianggap konstan.

Koefisien Regresi $\mathrm{X}_{2}$ (motivasi kerja) sebesar 0,447 yang berarti bahwa jika $\mathrm{X}_{2}$ (motivasi kerja) naik sebesar satu satuan, akan memberikan pengaruh terhadap kinerja karyawan sebesar koefisien pengalinya, dengan asumsi bahwa variabel lain dianggap konstan.

Uji statistik F atau uji signifikansi simultan, pada dasarnya menunjukkan apakah semua variabel bebas yang dimasukkan dalam model mempunyai pengaruh terhadap variabel dependen. Uji $\mathrm{F}$ ini dilakukan dengan membandingkan $\mathrm{F}_{\text {hitung }}$ dengan nilai $\mathrm{F}_{\text {tabel }}$ pada taraf nyata $\square=0,05$. Uji $F$ mempunyai pengaruh signifikan apabila $F_{h i t u n g}>$ (lebih besar) dari $\mathrm{F}_{\text {tabel }}$ atau probabilitas kesalahan kurang dari 5\% $(\mathrm{P}<0,05)$. 
Dari hasil perhitungan analisis Full Model Regression dengan bantuan program SPSS Versi 20.0 diperoleh bahwa pengembangan karir dan motivasi kerja memilki pengaruh terhadap kinerja karyawan pada PT. Pangkatan Indonesia.

Besarnya pengaruh (kontribusi) variabel bebas $(\mathrm{X})$ secara bersama-sama terhadap variabel tidak bebas $(\mathrm{Y})$ dapat dilihat dari besarnya koefisien determinan ganda $\left(\mathrm{R}^{2}\right)$ sebesar 0,330. Nilai koefisien determinasi adalah di antara nol dan satu. Jika $\mathrm{R}^{2}$ yang diperoleh dari hasil perhitungan semakin besar (mendekati 1), maka dapat dikatakan pengaruh variabel bebas terhadap variabel tidak bebasnya semakin besar. Atau dengan kata lain, jika nilai yang mendekati satu berarti variabel-variabel independen memberikan hampir semua informasi yang dibutuhkan untuk memprediksi variasi variabel dependen. Sebaliknya, jika $\mathrm{R}^{2}$ yang diperoleh dari hasil perhitungan semakin kecil (mendekati 0), maka dapat dikatakan pengaruh variabel bebas terhadap variabel terikat semakin kecil. Atau dengan kata lain, nilai $\mathrm{R}^{2}$ yang kecil berarti kemampuan variabel-variabel independen dalam menjelaskan variasi variabel dependen amat terbatas.

Uji t untuk menguji kemaknaan atau keberartian koefisien regresi partial. Pengujian melalui uji $t$ adalah dengan membandingkan $t_{\text {hitung }}$ dengan $t_{\text {tabel }}$ pada taraf nyata $\square=0,05$. Uji $t$ berpengaruh signifikan apabila hasil perhitungan $t_{\text {hitung }}$ lebih besar dari $t_{\text {tabel }}$ ( $t_{\text {hitung }}>t_{\text {tabel }}$ ). Lebih jelasnya ditunjukkan pada Tabel 4.11 disajikan hasil perhitungan uji $\mathrm{t}$ dan koefisien determinasi partialnya sebagai berikut:

Tabel 1.5 Hasil Uji Student (Uji-T)

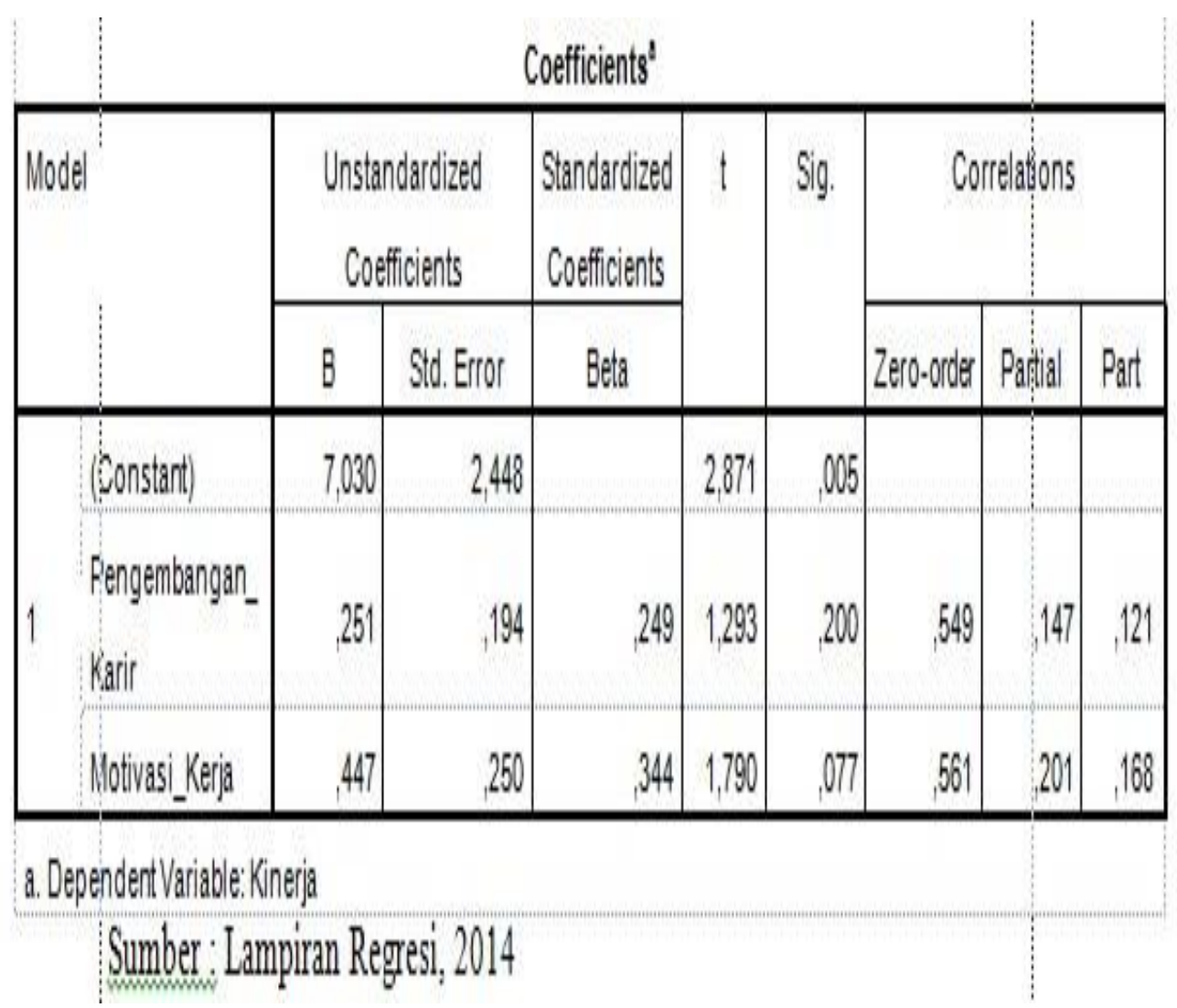



berikut:

Tabel diats menunjukkan pengujian variabel-variabel bebas dijabarkan sebagai

1. Variabel pengembangan karir $\left(X_{1}\right), T_{\text {hitung }} 1,293$ dan $T_{\text {tabel }}$ pada $\square=0,05$ sebesar 1,664 , hal ini berarti bahwa posisi signifikansi dan $\mathrm{T}_{\text {hitung }}$ pada kurva distribusi normal berada pada wilayah penolakan $\mathrm{H}_{\mathrm{a}}$ dengan demikian $\mathrm{H}_{\mathrm{a}}$ yang menyatakanbahwa terdapat pengaruh yang signifikan antara pengembangan karir $\left(\mathrm{X}_{1}\right)$ terhadap kinerja karyawan PT. Pangkatan Indonesia ditolak, yang berarti bahwa $\mathrm{H}_{\mathrm{o}}$ yang menyatakan bahwa tidak terdapat pengaruh yang signifikan antara pengembangan karir $\left(\mathrm{X}_{1}\right)$ terhadap kinerja karyawan PT. Pangkatan Indonesia diterima.

2. Variabel motivasi kerja $\left(X_{2}\right), T_{\text {hitung }} 1,790$ dan $T_{\text {tabel }}$ pada $\square=0,05$ sebesar 1,664 , hal ini berarti bahwa posisi signifikansi dan $\mathrm{T}_{\text {hitung }}$ pada kurva distribusi normal berada pada wilayah penolakan $\mathrm{H}_{\mathrm{o}}$ dengan demikian $\mathrm{H}_{\mathrm{o}}$ yang menyatakan bahwa tidak terdapat pengaruh yang signifikan antara motivasi kerja $\left(\mathrm{X}_{2}\right)$ terhadap kinerja karyawan PT. Pangkatan Indonesia di tolak, yang berarti bahwa $\mathrm{H}_{a}$ yang menyatakan bahwa terdapat pengaruh yang signifikan antara pengembangan karir $\left(\mathrm{X}_{2}\right)$ diterima.

Berdasarkan uraian interpretasi di atas diketahui bahwa variabel Motivasi kerja yang dominan berpengaruh terhadap kinerja karyawan PT. Pangkatan Indonesia. Dengan demikian, hipotesis dari penelitian ini belum dapat diterima sepenuhnya kebenarannya.

\section{KESIMPULAN}

Berdasarkan analisis yang telah dilakukan maka dapat diperoleh kesimpulan bahwa terdapat pengaruh yang signifikan antara pengembangan karir (variabel $\mathrm{X}_{1}$ ) terhadap kinerja karyawan, sebaliknya tidak terdapat pengaruh yang signifikan antara motivasi kerja (variabel $\mathrm{X}_{2}$ ) terhadap kinerja karyawan. Hal ini menunjukkan bahwa kebijakan pengembangan karir yang diterapkan manajemen PT. Pangkatan Indonesia mempengaruhi tingkat kinerja karyawan yang terlihat melalui dedikasi, loyalitas dan prestasi kerja karyawan.

\section{DAFTAR PUSTAKA}

As'ad, Moh. 2004. Organisasi dan Manajemen, Perilaku Struktur dan ProsesJakarta: Erlangga.

Gomes, Faustino Cardoso, 2003. Manajemen Sumber Daya Manusia, Yogyakarta: Penerbit Andi.

Hadari, 2003. Kepemimpinan

Mengaktifkan Organisasi..

Jakarta: Universitas Terbuka/UPI-YAI, 
Halmard, George, 2008. Development of HRM in Work. Published by John Wiley and Sons, New York.

Hans, James, 2007. Human Resources Management. Ninth Edition, UpperSaddle River, Prentice Hall, New Jersey.

Husnan, Suad, 1994. ManajemenPersonalia, Edisi ketiga, Yogyakarta: BPFE.

Istijanto, 2006. Metode Penelitian Kuantitatif, Yogyakarta: UPP YKPN.

Listianto, Tony dan Setiaji, Bambang, 2005. Pengaruh Motivasi, Kepuasan, Dan Disiplin Kerja Terhadap Kinerja Karyawan (Studi Kasus di Lingkungan Pegawai Kantor PDAM Kota Surakarta)

Mangkunegara, 2001. Manajemen Sumber Daya Manusia Perusahaan, Bandung : PT. Remaja Rosdakarya Offset.

Mangkuprawira, Syafri dan Hubeis, Aida Vitayala, 2007. Manajemen Mutu Sumber Daya Manusia, Jakarta: PT. Ghalia Indonesia.

Mas'ud, Fuad. 2004.Survai Diagnosis Organisasional: Konsep dan Aplikasi. Semarang : Badan Penerbit Universitas Diponegoro.

Mathis, Robert L dan Jackson, John, 1990. Manajemen Sumber daya manusia.Penerbit Salemba Empat, Jakarta.

Phoobe, French dan Steband, Newer, 2007. Organization Management.Published by Library State, California.

Prabu, Anwar Mangkunegara, 2004. Manajemen Sumber Daya Manusia Perusahaan, Bandung: Penerbit Remaja Rosdakarya.

Robbins, S. 2006. Organization Behavior, 9th EdNew Jersey, USA. Prentice-Hall International, Inc.

Sastrowiharjo, Siswanto, 2006. Manajemen Tenaga Kerja Indonesia, Jakarta : Bumi Aksara.

Siagian, Sondang, 2001. Manajemen Sumber Daya Manusia. Jakarta : . Bumi Aksara.

Simamora, Henry . 2006. Manajemen Sumber Daya Manusia. Jakarta : Gramedia Pustaka Utama.

Sudjana, Nana. 2010. Metode Statistika. Bandung: Tarsito.

Sugiyono. 2003. Metode Penelitian Bisnis. Bandung: Alfabeta. 
Suherman, E. (2003). Petunjuk Praktis untuk Melaksanakan Evaluasi Pendidikan Matematika. Bandung: Wijayakusumah.

Sukmawati, Farina, 2008. Pengaruh Kepemimpinan, Lingkungan Kerja Fisik,dan Konpensasi terhadap Kinerja Karyawan di PT. Pertamina (Persero) UPMS III Terminal Transit Utama Balongan, Indramayu.Jurnal JEB Vol. 2 No. 4 November.

Tudero, 2004. Manajemen Sumber Daya Manusia. Penerbit PT. Gramedia Pustaka Utama, Jakarta.

Umar, Husein, 2002. Metode Riset Bisnis, Jakarta: PT.Gramedia Pustaka Utama,

Winardi, 2000. Kepentingan dalam Manajemen, Yogyakarta: STIE.

Watimena, Abubakar, 2007. Pengaruh Motivasi, Perilaku Pemimpin, dan Kesempatan Pengembangan Karir terhadap Kinerja Karyawan pada Dinas Pendapatan Daerah Kabupaten Biak Papua, Jurnal Eksekutif Vol. 4 No. 3 Desember. 